\title{
Smart Monitoring Hidroponik Berbasis Internet of Things
}

\author{
Muh Fahmi Rustan *1, Muh Fuad Mansyur ${ }^{2}$, Muh Abrar Akbar ${ }^{3}$ \\ 1,2,3 Program Studi Teknik Informatika, Universitas Sulawesi Barat \\ e-mail:*1 muhfahmi@unsulbar.ac.id, ${ }^{2}$ muh.fuadm@unsulbar.ac.id, \\ ${ }^{3} \mathrm{~d} 02$ abrarakbar@unsulbar.ac.id
}

\begin{abstract}
Abstrak
Smart farming atau smart agriculture adalah pengaplikasian internet of things keladam sebuah sistem pertanian konvensional. Implementasi smart system keladam sebuah pertanian hidroponik dapat membantu petani dalam memaksimalkan hasil pertaniannya karena dapat mengontrol kebutuhan nutrisi sesuai dengan kebutuhan tanaman, sistem yang dibangun memantau dan menjaga kondisi tanaman hidroponik agar tetap dalam kondisi normal, nutrisi (ppm) yang dibutuhkan tanaman selada 560-840 ppm. Penelitian ini menggunakan logika fuzzy dalam mengatur kebutuhan nutrisi tanaman hidroponik, hasil sistem yang dibuat dapat malakukan pemantauan kondisi Nutrisi, PH Air dan Ketinggian Air secara realtime serta diperoleh hasil pengujian akurasi terhadap sistem sebesar $98.16 \%$.
\end{abstract}

Kata kunci-Internet of things, logika fuzzy, tds, hidroponik

\begin{abstract}
Smart farming or smart agriculture is the application of Internet of Things into a conventional farming system. The implementation of smart system into hydroponic farming helps farmers to maximize their agricultural products that can control nutrients according to the plant needs.The built system monitors and maintains the condition of hydroponic plants in order to keep the plants in a normal condition. The lettuce plant needs 560-840 nutrient (ppm) This research used fuzzy logic in regulating the nutritional needs of hydroponic plants. The result of this research shows that the system created can monitor the conditions of Nutrition, PH, and Water Level in real time hence the accuracy testing of the system are $98.16 \%$.
\end{abstract}

Keywords-Internet of things, fuzzy logic, tds, hydroponic

\section{PENDAHULUAN}

Smart farming adalah penerapan Internet of Things untuk menanam tanaman dengan kemampuan untuk melakukan penghematan tenaga kerja dan sumber daya[1]. Saat ini kebutuhan pangan yang melonjak tinggi di pasaran khususnya seperti sayuran dan buah- buahan, seiring perkembangan jumlah penduduk. Namun hal itu tidak dibarengi dengan pertumbuhan lahan pertanian yang justru semakin sempit [2]. Pertanian merupakan sektor yang sangat penting bagi masyarakat Indonesia. Sektor pertanian sebagai sumber penghasilan bagi masyarakat, karena sebagian besar kawasan Indonesia adalah wilayah pertanian. Melihat banyaknya lahan yang di pakai oleh masyarakat sebagai lahan pemukiman, maka saat ini ada cara lain untuk memanfaatkan lahan sempit sebagai usaha dalam mengembangkan hasil pertanian, yaitu dengan cara bercocok tanam secara hidroponik [3] 
Petani kadang menemui kendala seperti tidak maksimalnya hasil panen yang dikarenakan tidak memperhatikan kualitas air yang digunakan. Penyerapan larutan nutrisi merupakan komponen utama dari budidaya hidroponik. Seringkali larutan nutrisi yang diberikan tidak dapat diserap tanaman karena aliran larutan nutrisi yang tidak dapat merata di seluruh permukaan talang sehingga akar yang tidak terkena atau tersentuh aliran nutrisi mengakibatkan pertumbuhan tanaman terhambat [2].

Pertumbuhan tanaman hidroponik sangat dipengaruhi oleh media airnya, pada akhirnya akan mempengaruhi hasil produksi tanaman tersebut Pemantauan berkelanjutan dan tindakan korektif diperlukan untuk pertumbuhan tanaman yang sehat [4]. Untuk memberikan nutrisi yang baik pada tanaman diberikan nutrisi $\mathrm{AB}$ Mix, yang terdiri dari unsur micro (A) dan unsur macro (B). Pada unsur A (macro) mengandung campuran kalium nitrat, dan zat besi. Sedangkan unsur B (micro) mengandung campuran kalium di-hidro fostat, ammonium sulfat, kalium sulfat, seng sulfat serta berbagai unsur lainnya [5].

Untuk dapat mengatasi kebutuhan nutrisi diperlukan sebuah sistam yang dapat mengontrol pemberian nutrisi secara otomatis dan memonitoring tingkat keasaman $(\mathrm{pH})$ Otomasi mengurangi kesalahan manusia dan dapat meningkatkan akurasi dan stabilitas[6], sistem yang digunakan yaitu mikrokontroler ESP32 sebagai sistem utama untuk memperoleh data dari Sensor TDS (Total Dissolved Solid) dimana memiliki fungsi sebagai pendeteksi kadar ppm atau nutrisi yang akan dialirkan pada pipa paralon untuk mendistribusikan nutrisi pada tanaman, air akan mengalir secara terus menerus agar nutrisi tidak mengendap di dalam pipa paralon yang dapat menyebabkan tanaman tidak dialiri nutrisi secara merata. Penggunaan metode Fuzzy logic dalam sistem ini sebagai pengatur pemberian nutrisi AB Mix agar sesuai dengan kebutuhan nutrisi tanaman. Untuk mengetahui bagaimana sistem bekerja dengan baik atau mengetahui kadar nutrisi yang dibutuhkan oleh tanaman dibutuhkan teknologi IoT agar dapat mengetahui kadar $\mathrm{ppm} /$ nutrisi dan $\mathrm{pH}$ pada tanaman secara realtime.

\section{METODE}

Metode dalam merancang smart monitoring hidroponik berbasis Internet of Things ini adalah metode research and development[7]. Model pengembangan sistem ini mengacu pada model pengembangan ADDIE yaitu dengan melakukan analisis, desain, pengembangan, implementasi, dan evaluasi[8]. Prosedur dalam penelitian ini dapat dijelaskan dalam gambar 1.

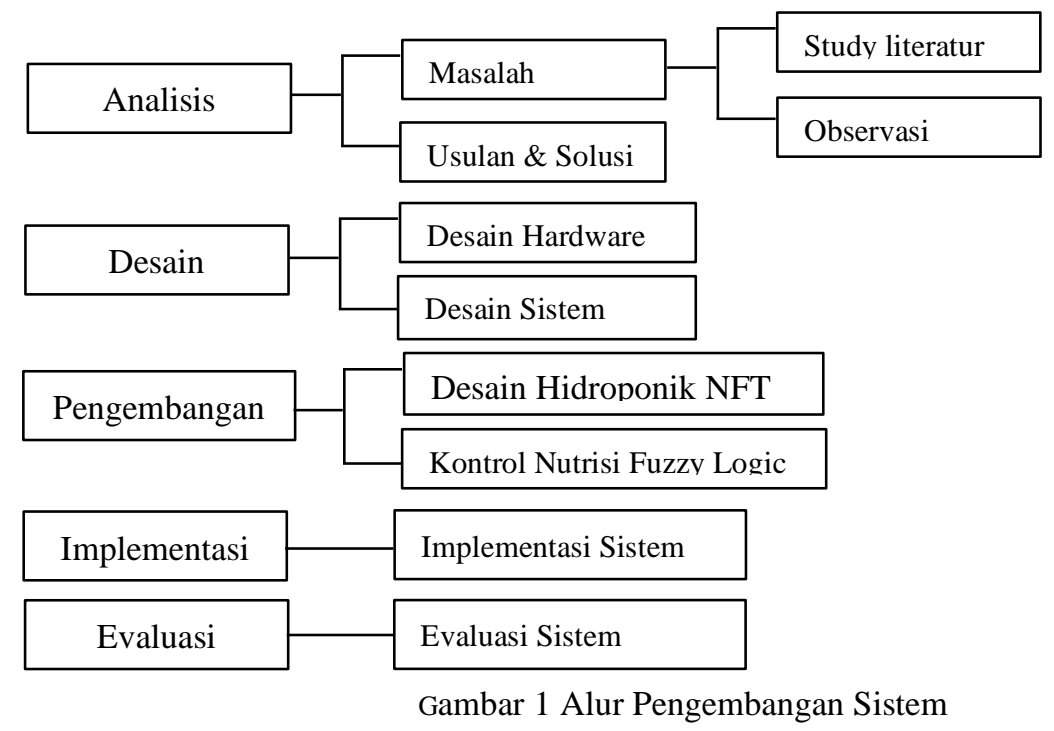

Title of manuscript is short and clear, implies research results (First Author) 


\subsection{Analisis}

Pada tahap ini dilakukan tahapan identifikasi masalah melalui studi literatur dengan mengumpulkan kebutuhan seperti waktu yang dibutuhkan tanaman selada dalam pertumbuhannya, berapa jumlah ppm atau nutrisi dan kadar $\mathrm{pH}$ yang dibutuhkan tanaman, berapa takaran pencampuran nutrisi $\mathrm{AB}$ Mix yang dituangkan ke wadah Langkah selanjutnya mendefinisikan format seluruh perangkat lunak, mengidentifikasikan semua kebutuhan, dan garis besar sistem yang akan dibuat seperti cara kerja ESP32, sensor TDS, sensor pH, sensor ultrasonik, relay dan pompa air serta proses kerja alur fuzzy logic sebagai pengatur cairan nutrisi yang akan dituangkan kedalam wadah nutrisi hidroponik.

\subsection{Desain}

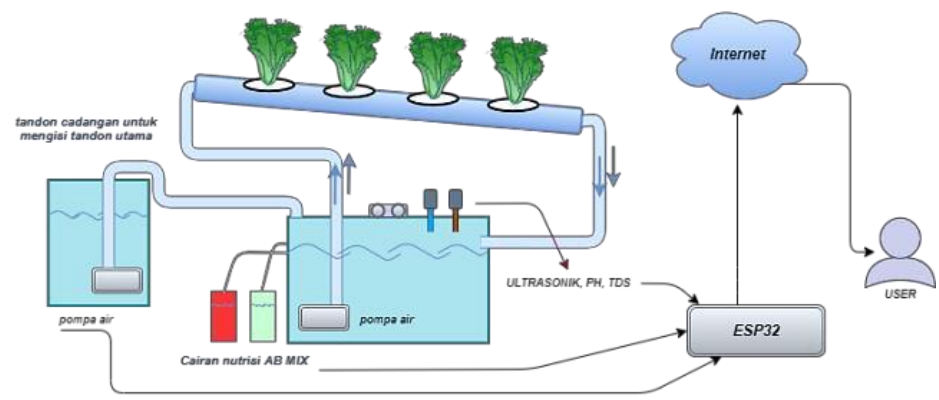

Gambar 2 Desain Perancangan

Pada gambar 2 menunjukkan desain perancangan hidroponik NFT yang dibuat. Hidroponik sistem NFT yang dirancang memiliki bagian-bagian seperti talang, selang, yang berfungsi sebagai media dalam memberikan nutrisi yang dialirkan dari wadah, netpot sebagai wadah untuk menyimpan tanaman, botol sebagai penyimpan cairan nutrisi A dan B, rangka pipa yang berguna sebagai penopang talang, pompa air untuk memompa air wadah dan air cadangan yang ada pada wadah air cadangan apabila air pada wadah utama berkurang, mikrokontroler ESP32 sebagai pengendali utama dari sensor TDS yang menampilkan data ppm, sensor $p H$ yang menampilkan kadar keasaman pada air, serta sensor ultrasonik membaca ketinggian air pada wadah, hasil pembacaan sensor dikirim ke user melalui internet.

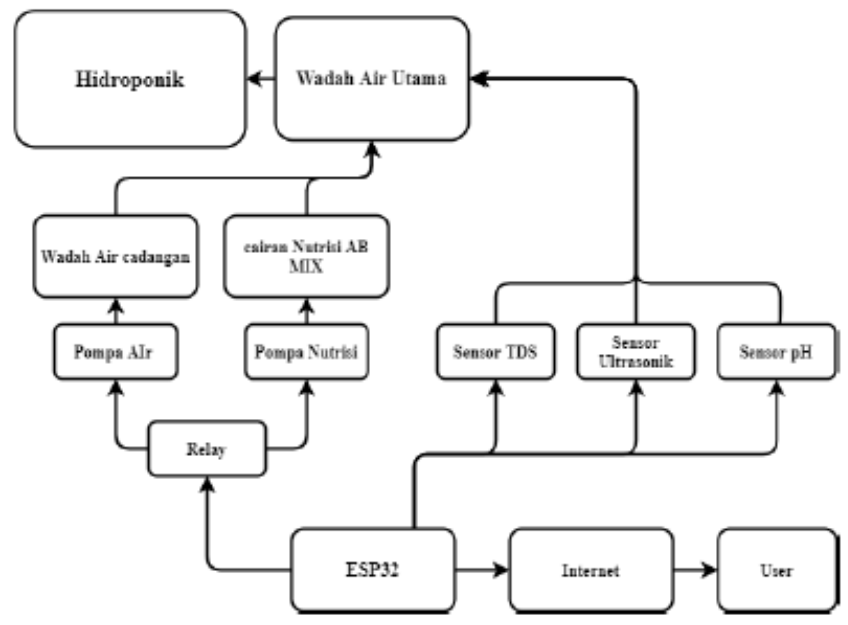

Gambar 3 Alur Pengembangan Sistem 
Gambar 3 merupakan perancangan hardware yang dimana Sensor TDS mendeteksi kadar nutrisi dan Sensor pH mendeteksi keasaman pada air dalam wadah. Ketika nutrisi rendah ESP32 akan memerintahkan relay untuk mengaktifkan pompa nutrisi bekerja, nutrisi yang sudah terlarut dalam wadah air dialirkan ke tanaman. Pompa cadangan air akan aktif ketika air pada wadah berkurang yang dideteksi dari pembacaan sensor Ultrasonik. Data sensor TDS, sensor $\mathrm{pH}$, dan sensor Ultrasonik dikirim ke user untuk menampilkan berapa nilai ppm, nilai kadar keasaman dan ketinggian air pada wadah air utama.

\subsection{Pengembangan}

Dalam penelitian ini, proses pengembangan yang dilakukan berupa perancangan sistem pemberian nutrisi otomatis menggunakan metode fuzzy logic, sistem dibuat dapat melakukan pemantauan terhadap kondisi air yang di atur menggunakan NTP Client. Informasi yang ditampilkan website dapat mengetahui berapa nutrisi/ppm, kadar keasaman $(\mathrm{pH})$ air dan banyaknya air pada wadah penjelasan penegmbangan sistem dapat dilihat pada gambar 3 .

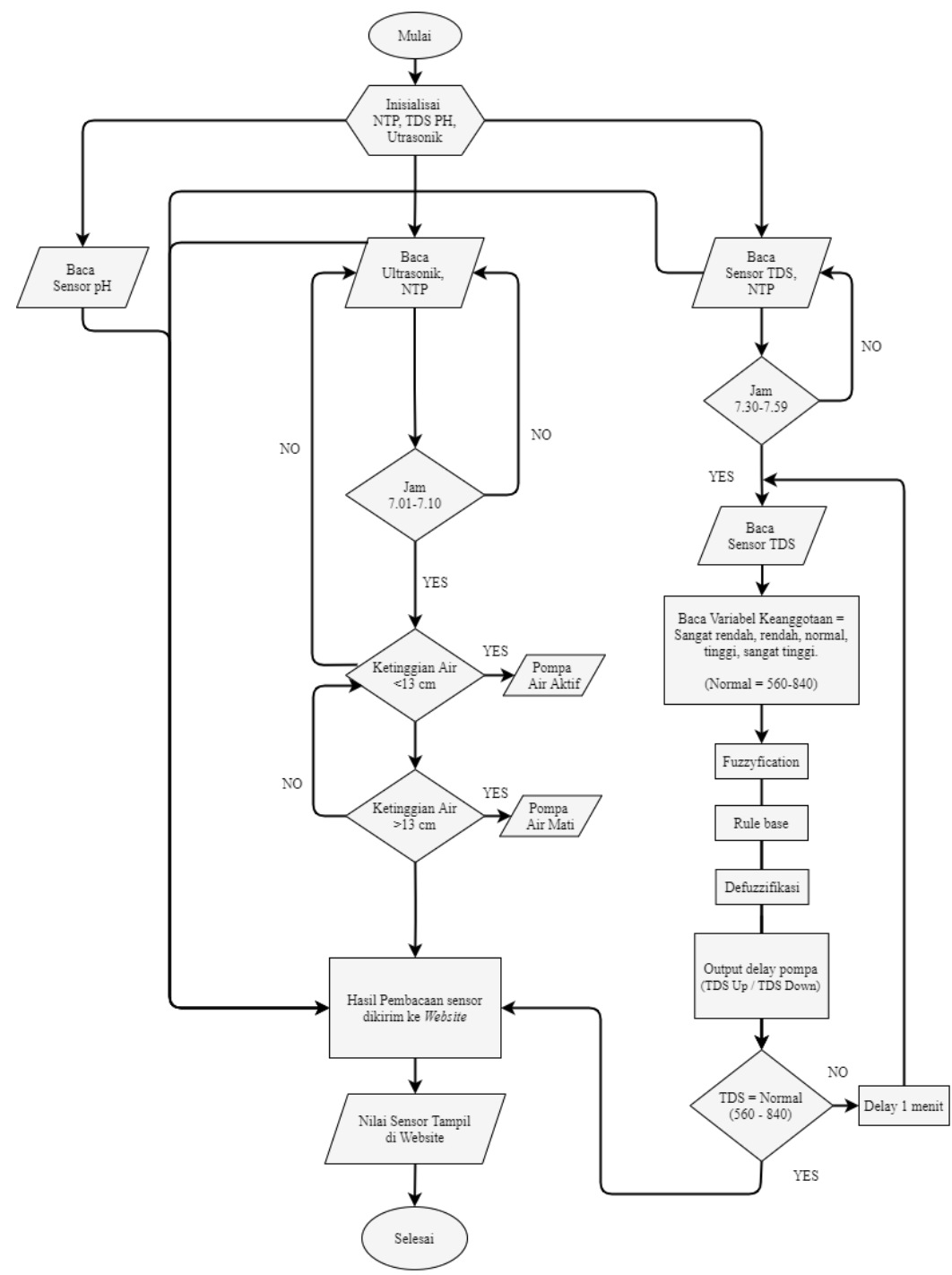

Gambar 4 Flowchart system smart monitoring hidroponik 
Gambar 4 merupakan flowchart system secara keseluruhan, untuk tahap pertama akan dilakukan inisialisasi sensor TDS, pH, ultrasonik serta NTP Client. Selanjutnya hasil pembacaan sensor TDS, pH, dan ultrasonik ditampilkan pada website secara realtime. Pada jam 07.01-07.10 sensor ultasonik aktif untuk melakukan cek kondisi ketinggian air, apabila sensor ultrasonik mendeteksi ketinggian air $<13 \mathrm{~cm}$ pompa akan aktif untuk mengisi wadah dan saat pembacaan ultrasonik mendeteksi $>13 \mathrm{~cm}$ pompa akan berhenti. Selanjutnya pada jam 07.30-07.59 sensor TDS akan aktif untuk mendeteksi kadar nutrisi yang kemudian dimasukkan pada variabel keanggotaan yang memiliki lima kondisi yaitu sangat rendah, rendah, normal, tinggi, dan sangat tinggi. Selanjutanya tahap fuzzification dimana nilai crips atau hasil pembacaan sensor TDS diubah dalam bentuk fuzzy yang kemudian ditentukan dalam rule base. Tahap akhir adalah proses defuzzifikasi yang dimana hasil rule base akan dikonversi kembali dalam bentuk crips yang berupa output delay untuk menghidupkan pompa TDS UP dan TDS DOWN. Saat angka normal ppm belum mencapai 560-840 ppm sistem akan kembali bekerja dengan jeda/delay waktu selama 1 menit kemudian kembali ke tahap pembacaan sensor TDS.

\subsection{Implementasi}

Tahap implementasi dilakukan setelah produk dievaluasi dan disetujui oleh pakar. Tahapan yang dilakukan dalam menguji kinerja perangkat yang dirancang dan untuk mengetahui kinerja masing-masing komponen. Komponen yang diuji antara lain sensor TDS, sensor Ultrasonik. Hasil pengujian komponen yang digunakan pada smart monitoring hidroponik dapat dilihat pada hasil dan pembahasan.

\subsection{Evaluasi}

Tahapan evaluasi dilakukan agar sistem yang telah dibuat sudah sesuai dengan yang diharapkan. Uji coba dilakukan dalam beberapa tahap uji coba (testing) diantaranya pengujian menggunakan blackbox, pengujian dengan membandingkan hasil pembacaan sensor-sensor yang digunakan dengan alat ukur konvensional yang terkalibrasi untuk membuktikan apakah aplikasi yang telah dibuat sudah sesuai dengan tujuan yang akan dicapai.

\section{HASIL DAN PEMBAHASAN}

Sistem yang dikembangkan telah berhasil melakukan monitoring dan mengatur kadar nutrisi air pada wadah hidroponik. Konektivitas dari internet sangat mendukung untuk melakukan proses monitoring dari jarak jauh. Sistem yang dibuat secara otomatis untuk mengambil data kondisi wadah air sehingga pengguna tidak harus lagi memantau kondisi nutrisi secara intensif. Hasil Perancangan hardware dengan menggabungkan semua komponen seperti sensor TDS, sensor $p H$, sensor Ultrasonik, dan relay, dengan ESP32. Penyambungan relay dengan pompa nutrisi AB Mix dan pompa cadangan air yang berfungsi sebagai Output, tahapan selanjutnya adalah melakukan pengujian untuk masing-masing sensor dan proses fuzzy.

\subsection{Pengujian Sensor TDS}

Hasil pengujian sensor TDS yang dibanding dengan hasil pembacaan TDS Meter pada Gambar 4.1.

Tabel 1 Pengujian Sensor TDS

\begin{tabular}{cccc}
\hline No & $\begin{array}{c}\text { Sensor TDS } \\
(P P M)\end{array}$ & $\begin{array}{c}\text { TDS Meter } \\
(P P M)\end{array}$ & Akurasi (\%) \\
\hline 1 & 906 & 996 & 90 \\
\hline
\end{tabular}

Title of manuscript is short and clear, implies research results (First Author) 


\begin{tabular}{cccc}
\hline No & $\begin{array}{c}\text { Sensor TDS } \\
(P P M)\end{array}$ & $\begin{array}{c}\text { TDS Meter } \\
(P P M)\end{array}$ & Akurasi (\%) \\
\hline 2 & 819 & 850 & 96 \\
3 & 740 & 781 & 94 \\
4 & 662 & 669 & 98 \\
5 & 627 & 642 & 97 \\
6 & 532 & 546 & 97 \\
\hline
\end{tabular}

Berdasarkan tabel 1 yang dilakukan percobaan sebanyak 6 sampel diperoleh rata-rata akurasi sebesar 95,33\%, hasil pengujian sensor yang dibandingkan dengan TDS Meter memiliki selisih yang tidak terlalu jauh dengan nilai sensor TDS meter yang terhubung pada mikrokontroller.

\subsection{Pengujian Sensor Ultrasonik}

Pengujian sensor ultrasonik dilakukan untuk memperoleh jarak yang dihasilkan oleh sensor ultrasonik yang dibandingkan dengan jarak menggunakan alat ukur penggaris.

\begin{tabular}{llll} 
& \multicolumn{3}{l}{ Tabel 2 Pengujian Sensor Ultrasonik } \\
\hline \multirow{2}{*}{ No } & \multicolumn{2}{c}{ Jarak (cm) } & Akurasi \\
& Sensor & Penggaris & $(\%)$ \\
& Ultrasonik & & 97 \\
\hline 1 & 16.5 & 16.9 & 97 \\
2 & 14.2 & 14.5 & 98 \\
3 & 13.3 & 13.5 & 97 \\
4 & 10.7 & 11 & 97 \\
5 & 9.7 & 10 & \\
\hline
\end{tabular}

Berdasarkan tabel 2 yang dilakukan percobaan sebanyak 5 sampel diperoleh rata-rata akurasi sebesar $97,2 \%$. hasil pengujian sensor yang dibandingkan dengan alat ukur penggaris dimana sesuai datasheet yang menerangkan bahwa akurasi mencapai $\pm 3 \mathrm{~mm}$.

\subsection{Implementasi Fuzzy Logic}

Implementasi fuzzy logic diawali dengan tahapan penentuan Membership Function Input yang memiliki lima variabel keanggotaan, dan Membership Output yang berupa delay (millisecond) dengan tiga kondisi.

Tabel 3 Membership Function Input

\begin{tabular}{lllll}
\hline \multirow{2}{*}{ Keterangan } & \multicolumn{4}{c}{ Ranges $(\mathrm{ppm})$} \\
\cline { 2 - 5 } (SR) Sangat rendah & $\mathrm{A}$ & $\mathrm{B}$ & $\mathrm{C}$ & $\mathrm{D}$ \\
(R) Rendah & 200 & 400 & 400 & 560 \\
Normal & 400 & 560 & 840 & 900 \\
(T) Tinggi & 840 & 900 & 900 & 1000 \\
(ST) Sangat tinggi & 900 & 1000 & 1200 & 1200 \\
\hline
\end{tabular}

Title of manuscript is short and clear, implies research results (First Author) 
Tabel 3 menunjukkan range ppm yang memiliki lima variabel yaitu : sangat rendah, rendah, normal, tinggi, sangat tinggi. Nilai ranges dari 0-1200 dalam satuan ppm (part per million). Yang di visualisasikan pada membership function input pada gambar 5.

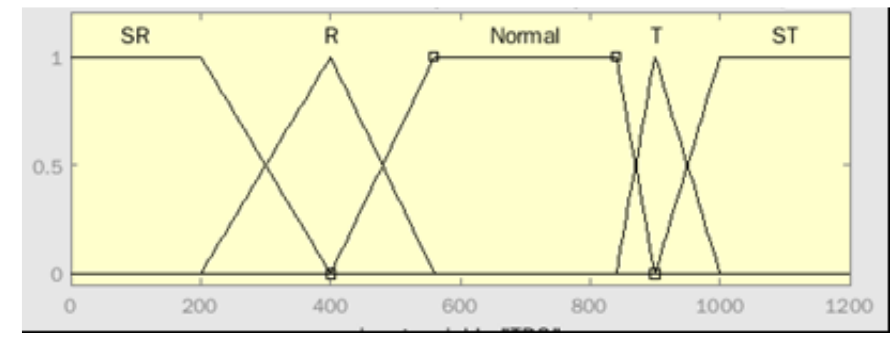

Gambar 5

Tabel 4 menunjukkan nilai Ranges delay yang memiliki tiga kondisi yaitu stop, sedikit dan banyak. Nilai Ranges dari 0-9000 dalam satuan milisecond sebagai output yang mengatur durasi waktu untuk menyalakan pompa.

Tabel 4 Membership Function Output

\begin{tabular}{lllll}
\hline \multirow{2}{*}{ Keterangan } & \multicolumn{4}{c}{ Ranges (milisecond) } \\
\cline { 2 - 5 } & A & B & C & D \\
\hline Stop & 0 & 0 & 0 & 0 \\
Sedikit & 1000 & 5000 & 5000 & 7000 \\
Banyak & 7000 & 8000 & 9000 & 9000 \\
\hline
\end{tabular}

Tahap perancangan Inference sistem pada tabel 5, inference melakukan penalaran untuk mengambil kesimpulan dalam bentuk rule base/aturan.

Tabel 5 Inference Sistem

\begin{tabular}{llll}
\hline \multirow{2}{*}{ No } & Input & \multicolumn{2}{c}{ Output } \\
\cline { 2 - 4 } & TDS & TDS UP & TDS DOWN \\
\hline 1 & Sangat rendah & Banyak & Stop \\
2 & Rendah & Sedikit & Stop \\
3 & Normal & Stop & Stop \\
4 & Tinggi & Stop & Sedikit \\
5 & Sangat tinggi & Stop & Banyak \\
\hline
\end{tabular}

Tahapan akhir dalam fuzzy logic ialah defuzzifikasi dimana hasil pembacaan sensor yang sebelumnya diubah ke fuzzy kemudian ditentukan pada rule base yang kembali menjadi nilai 
bilangan asli yang berbentuk output delay dari membership output hasilnya dapat dilihat pada gambar 6.

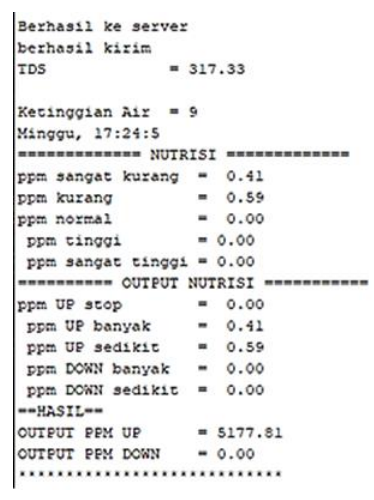

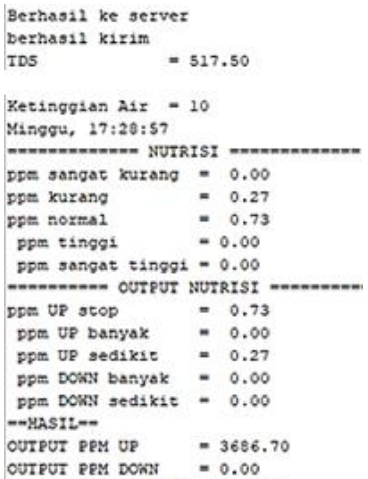

OUTPUT PEM DOKS $=0.00$

Gambar 6

3.4 Hasil perancangan sistem monitoring
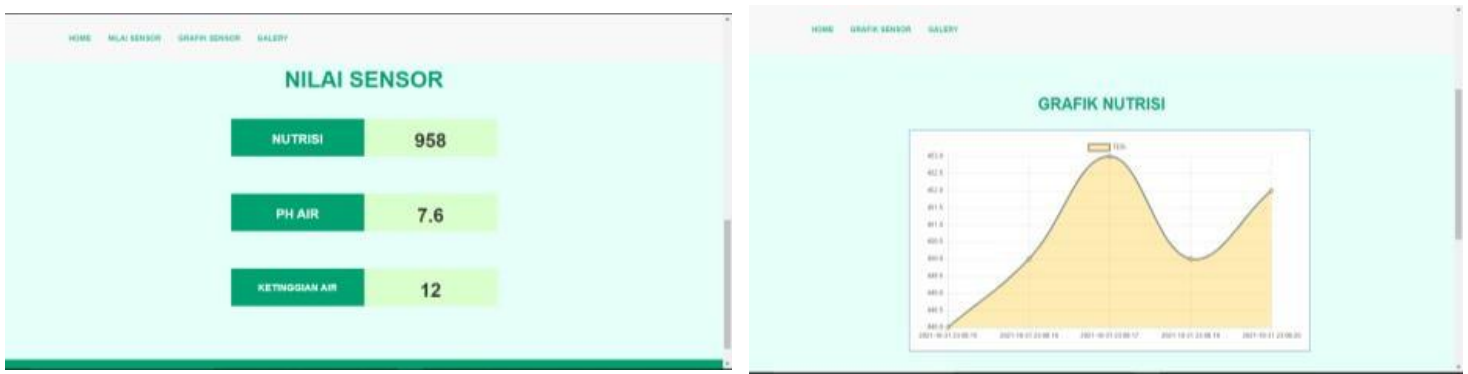

Gambar 7

Gambar 7 merupakan hasil perancangan sistem dibuat dalam bentuk tampilan web secara realtime dimana pengguna dapat melihat data $\mathrm{ppm}, \mathrm{pH}$ air, dan ketinggian air pada wadah secara realtime. Aplikasi web juga mendukung pembacaan nilai sensor TDS yang ditampilkan dalam bentuk grafik.

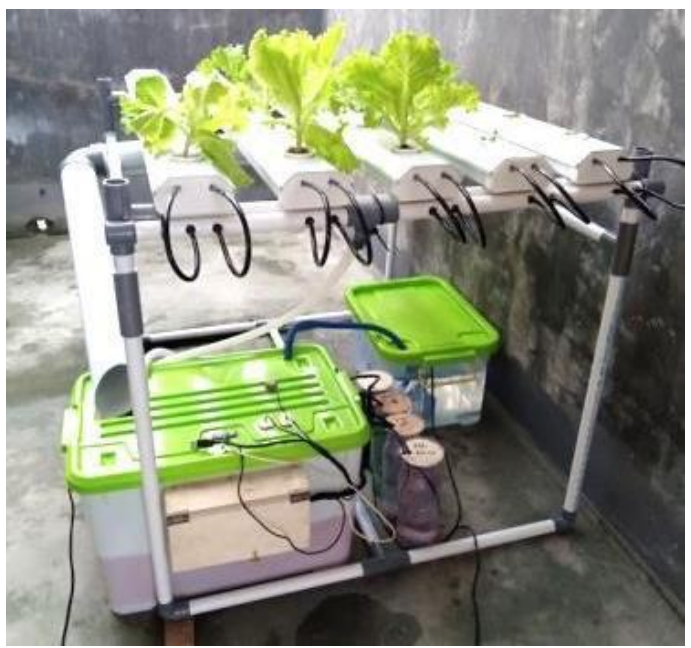

Gambar 8

Title of manuscript is short and clear, implies research results (First Author) 
Smart monitoring hidroponik yang telah dirancang dapat dilihat pada gambar 8. Hasil perancangan hidroponik menggunakan metode NFT dengan sistem otomasi nutrisi menggunakan fuzzy logic berhasil dibuat. Untuk melakukan monitoring dapat menggunakan smartphone atau komputer yang terkoneksi dengan internet, mikrokontroler ESP32 sebagai pengendali utama dari sensor TDS yang menampilkan data ppm, $\mathrm{pH}$ serta ketinggian air.

\subsection{Tahapan pengujian sistem}

Tahap pengujian sistem, setelah melakukan perancangan hardware dan software tahapan selanjutnya melakukan pengujian dan analisa terhadap sistem dan alat yang telah dibuat. Apakah sistem dan alat dapat bekerja dengan baik sesuai dengan fungsi dan kegunaan perancangannya. Tahap pengujian bertujuan untuk melihat kemungkinan kesalahan yang terjadi dari setiap proses yang berjalan. Adapun pengujian sistem yang dilakukan adalah pengujian Black Box atau pengujian fungsional merupakan metode pengujian tanpa mengetahui struktur internal kode atau program yang dimana dapat mengetahui apakah fungsi dari sistem yang telah dibuat sudah berjalan dengan baik.

Tabel 6 pengujian sistem

\begin{tabular}{llll}
\hline $\begin{array}{l}\text { Waktu } \\
\text { NTP } \\
\text { Client }\end{array}$ & Kondisi & Hasil yang diharapkan & Pengamatan \\
\hline 07:01 & $\begin{array}{l}\text { Pompa } \\
\text { Aktif }\end{array}$ & $\begin{array}{l}\text { Pada pukul 7.01 pompa air } \\
\text { aktif jika Ultrasonik } \\
\text { Membaca pada ketinggian } \\
\text { di bawah 13 cm. }\end{array}$ & $\begin{array}{l}\text { Pompa air Mengisi wadah } \\
\text { air utama }\end{array}$ \\
07:06 & $\begin{array}{l}\text { Pompa } \\
\text { Mati pukul 7.06 pompa air } \\
\text { tidak aktif saat Ultrasonik } \\
\text { membaca pada ketinggian di } \\
\text { atas 13 cm. } \\
\text { Pada pukul 7.10 pompa air } \\
\text { mati }\end{array}$ & $\begin{array}{l}\text { Pompa air mati saat } \\
\text { ditentukan Keting }\end{array}$ \\
07:10 & $\begin{array}{l}\text { Pompa air tetap mati, } \\
\text { waktu sudah selesai }\end{array}$ \\
\hline
\end{tabular}

Berdasarkan tabel 6, penambahan air pada wadah utama berjalan sesuai dengan pewaktuan dan pembacaan ultrasonik. Pompa cadangan air akan aktif pada jam 7.01 dan ultrasonik membaca ketinggian air di bawah $13 \mathrm{~cm}$. Saat ketinggian air mencapai diatas $13 \mathrm{~cm}$ pompa akan mati. Pompa akan menyala selama 10 menit kedepan, sebagai rentang waktu dalam pengisian air.

Tabel 7 Pengujian Fuzzy Logic

\begin{tabular}{|c|c|c|c|c|c|}
\hline Input & & Output & & & \\
\hline $\begin{array}{c}\text { Kadar nutrisi } \\
\quad(\text { ppm })\end{array}$ & $\begin{array}{l}\text { Output } \\
\text { Sistem }\end{array}$ & $\begin{array}{l}\text { Output } \\
\text { Matlab }\end{array}$ & $\begin{array}{l}\text { Output } \\
\text { Sistem }\end{array}$ & $\begin{array}{l}\text { Output } \\
\text { Matlab }\end{array}$ & Akurasi (\%) \\
\hline 7 & 7916 & 8250 & - & - & $96,0 \%$ \\
\hline 274 & 5753 & 5670 & - & - & $98,5 \%$ \\
\hline 317 & 5177 & 5160 & - & - & $99,7 \%$ \\
\hline 431 & 4311 & 4290 & - & - & $99,5 \%$ \\
\hline
\end{tabular}

Title of manuscript is short and clear, implies research results (First Author) 


\begin{tabular}{|c|c|c|c|c|c|}
\hline Input & & Output & & & \\
\hline $\begin{array}{l}\text { Kadar nutrisi } \\
\quad(\text { ppm })\end{array}$ & $\begin{array}{l}\text { Output } \\
\text { Sistem }\end{array}$ & $\begin{array}{l}\text { Output } \\
\text { Matlab }\end{array}$ & $\begin{array}{l}\text { Output } \\
\text { Sistem }\end{array}$ & $\begin{array}{l}\text { Output } \\
\text { Matlab }\end{array}$ & Akurasi (\%) \\
\hline 517 & 3686 & 3940 & & & $93,6 \%$ \\
\hline 528 & 3641 & 3840 & - & - & $94,8 \%$ \\
\hline 662 & 0 & 0 & 0 & 0 & $100,0 \%$ \\
\hline 824 & 0 & 0 & 0 & 0 & $100,0 \%$ \\
\hline 934 & - & - & 5013 & 5020 & $99,9 \%$ \\
\hline 1000 & - & - & 8222 & 8250 & $99,7 \%$ \\
\hline
\end{tabular}

Berdasarkan tabel 7 menunjukkan nilai pembacaan kadar nutrisi (ppm), hasil output TDS UP dan output TDS DOWN dari hasil percobaan sebanyak 10 sampel menunjukkan perbandingan output yang dihasilkan fuzzy logic dan output dari Matlab tidak jauh berbeda dengan akurasi sebesar $98,16 \%$.

\section{KESIMPULAN}

Berdasarkan hasil pengujian dan analisis kontrol nutrisi air pada tanaman hidroponik berbasis mikrokontroler, maka dapat disimpulkan, Hasil rancangan kontrol nutrisi air pada tanaman hidroponik berbasis mikrokontroler telah berhasil dibuat. Sistem akan berjalan secara otomatis pada pukul 07.01-07.10, pada rentang waktu ini pompa cadangan air akan berjalan untuk menambahkan air pada tandon utama apabila ketinggian air pada wadah kurang dari $13 \mathrm{~cm}$ dan akan berhenti pada ketinggian $>13 \mathrm{~cm}$. Pada jam 07.30-07.59, sistem kembali berjalan untuk menambahkan nutrisi. Hasil pembacaan sensor TDS yang dimasukkan dalam variabel keanggotaan fuzzy logic yang menghasilkan output delay berbeda-beda untuk menyalakan pompa nutrisi A dan B sehingga dapat menstabilkan nutrisi. Nutrisi atau ppm normal dari selada sekitar 560-840 ppm, hasil pengujian yang dihasilkan oleh fuzzy logic melalui mikrokontroller yang dibandingkan dengan output dari aplikasi Matlab tidak jauh berbeda dan diperileh nilai akurasi sebesar $98,16 \%$.

\section{REFERENSI}

[1] T. Changmai, S. Gertphol, and P. Chulak, "Smart Hydroponic Lettuce Farm using Internet of Things," 2018 10th Int. Conf. Knowl. Smart Technol. Cybern. Next Decad. KST 2018, pp. 231-236, 2018, doi: 10.1109/KST.2018.8426141.

[2] W. S. P. Ahmad Yanuar Hadi Putra, "SISTEM KONTROL OTOMATIS PH LARUTAN NUTRISI TANAMAN BAYAM PADA HIDROPONIK NFT (NUTRIENT FILM TECHNIQUE)," J. Mikrotek, vol. 2, no. 4, pp. 11-20, 2017.

[3] I. P. Hasbi Fardian Nugraha, Susijanto Tri Rasmana, "PENGATURAN AIR DAN NUTRISI SECARA OTOMATIS PADA TANAMAN HIDROPONIK BERBASIS 
ARDUINO," JCONES - J. Control Netw. Syst., vol. 6, no. 2, p. 103, 2017.

[4] A. Mehboob, W. Ali, T. Rafaqat, and A. Talib, "Automation and Control System of EC and pH for Indoor Hydroponics System,” pp. 1-6, 2019, [Online]. Available: https://ieec.neduet.edu.pk/2019/Papers_IEEC_2019/IEEC_2019_33.pdf.

[5] V. Ivandito, "Realisasi Sistem Pengukuran Kadar Nutrisi, PH, dan Suhu pada Hidroponik Secara Jarak Jauh,” UNIVERSITAS KRISTEN MARANATHA., 2018.

[6] S. Adhau, R. Surwase, and K. H. Kowdiki, "Design of fully automated low cost hydroponic system using LabVIEW and AVR microcontroller," Proc. 2017 IEEE Int. Conf. Intell. Tech. Control. Optim. Signal Process. INCOS 2017, vol. 2018-February, no. March 2017, pp. 1-4, 2018, doi: 10.1109/ITCOSP.2017.8303091.

[7] A. A. Gde Ekayana, "Pengembangan Modul Pembelajaran Mata Kuliah Internet of Things," J. Pendidik. Teknol. dan Kejuru., vol. 16, no. 2, p. 159, 2019, doi: 10.23887/jptk-undiksha.v16i2.17594.

[8] R. M. Branch, Instructional Design: The ADDIE Approach. New York: Springer, 2009. 